\title{
A PRODUÇÃO DA PESCA INDUSTRIAL EM SANTA CATARINA
}

\author{
H.A. ANDRADE \\ CTTMar - UNIVALI \\ Rua Uruguai, 458, Cx.P. 360, Itajaí, SC - CEP 88.302-202 \\ humber@univali.rct-sc.br
}

\begin{abstract}
RESUMO
O Estado de Santa Catarina, um dos maiores produtores nacionais de pescado, possui uma frota numerosa e diversificada. As capturas das diversas frotas têm mostrado grandes oscilações anuais em termos de desembarque em peso, que interferem substancialmente na economia local e estadual. Com o objetivo de identificar as tendências e avaliar as causas das variações interanuais da captura foi feito um levantamento histórico dos dados disponíveis sobre a pescaria das diversas frotas a partir da década de 80. As maiores linhas catarinenses de pescado são em primeira instância as capturas de peixes pelas frotas de traineiras, parelhas e vara e iscaviva. A maioria das pescarias apresentaram o padrão comum de relação inversa entre o esforço despendido e a CPUE. O ano de 1991 da pesca de traineiras foi uma exceção, explicada pela implementação do defeso em 1990. Outra exceção ocorreu para a pesca de parelhas, explicada aparentemente pelo caráter extremamente multi-específico dessa pescaria. As oscilações e a tendência geral crescente de produção de pescado de 1989 a 1991, foram basicamente um reflexo das variações na pesca de traineiras. Entretanto, o incremento em 1993 é resultante de aumento generalizado dos esforços de pesca, onde destaca-se o grande desenvolvimento das pescas de caceio e de espinhel. Outro fator que contribuiu também para a tendência crescente de 1989 a 1993 foi provavelmente o aproveitamento nas pescarias de arrasto de fundo de espécies que antigamente eram tidas como rejeito.
\end{abstract}

Palavras Chave: Pesca Industrial, Santa Catarina, Brasil.

\section{INDUSTRIAL FISHING PRODUCTION IN SANTA CATARINA, SOUTHERN BRAZIL}

\begin{abstract}
The Santa Catarina State has a large and diversified fishing fleet and is placed among brasilian's main sea-food producers. Catches of the different fleets have oscilated substantially from year to year, which greatl affected local and state economy. The trends of such variations and their related causes were studied by analysing historical catch data available for the different fleets from 1989 to 1993. Three fishing methods are responsable for most of Santa Catarina's landings: purse-seine, pair trawling and pole-and-line. Most fisheries have shown a similar inverse pattern between fishing effort and CPUE with the exception of the purse-seiners during 1991, probably due to the implementation in the year before, of a harvesting tactic of season lenght limitation. Another exception was noted among pair trawlers partially explained by multi-specific nature of their catch. Oscillations and the overall increasing trend of total annual catches between 1989 and 1991 reflected variations of purse-seiners activities. A general increase in 1993 resulted from an increase on the effort of all fishing methods, and specially the development of drift-net and long-line fisheries. Another important contribution to that production increase was the more extensive use of by-catch species, maily caught by trawlers, that had been historically rejected.
\end{abstract}

Keywords: Industrial Fishery, Santa Catarina State, Brazil. 
ANDRADE: A produção da pesca industrial em Santa Catarina.

\section{INTRODUÇÃO}

Santa Catarina destaca-se no cenário nacional como um dos maiores produtores de pescado, possuindo um complexo industrial pesqueiro de grandes dimensões e uma frota de embarcações numerosa e diversificada. No estado a atividade é realizada em escala artesanal e industrial. A pescaria artesanal é exercida com pequenas embarcações, em regiões costeiras e mesmo estuarinas. Entretanto, a pescaria industrial abrange além das regiões costeiras, as regiões oceânicas mais profundas, sendo realizada por embarcações com maior tamanho, autonomia de navegação e tecnologia.

A produção pesqueira industrial supera em muito a artesanal, representando atualmente cerca de $94 \%$ do total desembarcado em peso no Estado de Santa Catarina (Andrade, 1997). Dessa forma, o segmento industrial constitui o ponto central da pesca catarinense, principalmente para a região do litoral centro-norte catarinense que tem grande parte de sua economia calcada na atividade pesqueira.

A produção pesqueira catarinense é realizada por várias frotas diferentes, com o emprego de diversificados apetrechos de pesca. Várias dessas pescarias são multi-específicas, ou seja, atuam sobre uma gama de espécies conjuntamente. Uma das conseqüências dessa conjugação de fatores, é a ocorrência de oscilações interanuais resultantes da combinação das variações no esforço de pesca empregado e dos rendimentos obtidos por cada uma das frotas. Além disso, o mercado pesqueiro é extremamente dinâmico com modificações de embarcações de uma frota para atuação em outra pescaria, e ainda com investimentos variáveis em cada pescaria, em função dos rendimentos que a mesma apresenta. Dessa forma a produção pesqueira catarinense tem apresentado oscilações significativas desde o início da década de 80 (Andrade, 1997). Dentro dessa perspectiva, a investigação da dinâmica produtiva das diversas frotas é imprescindível para um entendimento da dinâmica global, o que possibilita uma administração adequada e preditiva quanto ao direcionamento econômico da atividade pesqueira em Santa Catarina. Outro aspecto importante do acompanhamento do desenvolvimento da pescaria das diversas frotas, é a identificação de variações e oscilações que indiquem a necessidade de implementação de estudos direcionados mais específicos para discernimento do problema e a identificação de soluções administrativas.

\section{MATERIAL E MÉTODOS}

Os dados de pesca das diversas frotas foram obtidos através de informes sobre os desembarques controlados de pescados no estado de Santa Catarina, publicados regularmente pelo IBAMA/CEPSUL. As informações existentes nesses boletins não são detalhadas o suficiente para uma análise mais aprimorada. Por exemplo não há dados sobre o posicionamento na realização da pescaria, sobre o número de horas de arrasto para as frotas que trabalham com esse tipo de pesca, duração das viagens de pesca, distribuição sazonal do esforço de pesca, profundidade, etc... Quanto aos dados de capturas que constam nestes boletins, um aspecto que deve ser ressaltado é a forma com que eles são obtidos. Os dados são provenientes de notas fiscais, emitidas no momento do descarregamento e pesagem do pescado. No momento do descarregamento existem recursos capturados em pequena quantidade que nem mesmo são pesados ou medidos, sendo que os mesmos são levados para consumo dos próprios pescadores ou de agregados do processo de descarregamento. Além disso, frequentemente uma parte pequena da produção dos recursos capturados em quantidade, também são consumidos nesse processo de descarga, e nem mesmo chegam a ser pesados. Dessa forma as capturas reais tendem a ser subestimadas, o que implica em mais uma 
incerteza na base de dados. Entretanto, a percentagem não contabilizada da captura total é na verdade muito baixa. Além disso, na análise de uma série de dados anuais, esse problema certamente não mascara a tendência temporal da variação da captura.

O número de desembarques anuais de cada frota é o dado público disponível relativo ao esforço de pesca que mais se aproxima do que seria o ideal. Assim, optou-se por considerá-lo como um índice do esforço de pesca, mesmo que reconhecidamente o mesmo não seja uma unidade muito adequada para algumas pescarias. O uso do número de desembarques como esforço de pesca resulta certamente em alguns problemas para comparação entre os rendimentos das diferentes frotas. Por exemplo, a duração das viagens de traineiras é muito menor do que as de camaroeiros, sendo a captura por viagem de uma traineira realizada em mais ou menos 2 dias de pesca, enquanto que a de um camaroeiro é realizada em aproximadamente 12 dias de pesca. De qualquer forma, a comparação de rendimentos de pesca de frotas diferentes é sempre inviável, mesmo se estivessem disponíveis dados mais detalhados de cada pescaria, e na verdade não apresentam freqüentemente muita utilidade em análises ecológicas, sendo mais útil em uma análise econômica.

Apesar de haver problemas na comparação dos rendimentos de pesca entre diferentes frotas, uma análise a partir do número de desembarques por frota gera informações importantes acerca da variação temporal do esforço de pesca empregado e dos rendimentos obtidos por uma dada frota pesqueira. Ainda assim, é necessária alguma cautela na interpretação de resultados mesmo dentro de única frota. Mudanças nas tecnologias ou em algum ponto que aumente a eficiência de captura da frota no decorrer do período analisado, podem levar a conclusões errôneas. Por exemplo, a introdução de ecossondas na pesca de espécies pelágicas que formam cardumes pode aumentar a eficiência de pesca, e conseqüentemente 0 coeficiente de capturabilidade, de forma que a duração das viagens diminua e portanto possa ser realizado um maior número de desembarques em dado período de tempo. Assim, comparações de rendimentos de uma dada frota, com o uso do número de desembarques, em períodos anteriores e posteriores à introdução das ecossondas levaria a conclusões errôneas sobre as tendências temporais no rendimento da pescaria. Entretanto, especificamente nesse trabalho, assumiu-se para tratamento dos dados, que entre 1988 e 1993 não houveram modificações nas frotas que levassem a variações significativas no coeficiente de capturabilidade, a partir do uso do número de desembarques como unidade do esforço de pesca.

\section{RESULTADOS}

\section{Produção Pesqueira Industrial}

No início da década de 80 , houve um declínio acentuado da produção, em 1980 foram desembarcadas mais de 90 mil toneladas de pescado, enquanto que em 1981, a produção foi de cerca de 50 mil toneladas (Figura 1). Após esse declínio acentuado, houve uma tendência de crescimento gradativo da produção até 1984. Em 1985 houve uma explosão da produção que atingiu valores superiores a 100 mil toneladas. Essa grande produção não se manteve por muito tempo, ocorrendo uma queda acentuada em 1987, quando a quantia de pescado desembarcado foi de cerca de 60 mil toneladas. A partir de então até 1993, houve um crescimento gradativo da produção até cerca de 100 mil toneladas anuais (Figura 1).

No desembarque total em peso, os peixes representam claramente o principal produto pesqueiro, enquanto que os crustáceos (ex: camarões e siris) e os moluscos (ex: lulas, polvos, berbigões e mariscos) têm importância secundária quanto a volume de pesca- 
do (Figura 2). Dessa forma as variações no total descarregado a cada ano refletem basicamente as variações da quantidade de peixes capturados. Nos desembarques desse grupo de recurso pesqueiro, as maiores oscilações são determinadas pela pesca da sardinha e do bonito listado, que atuam decisivamente no total de pescado desembarcado.

Apesar da pouca importância em peso desembarcado, os crustáceos são economicamente bastante importantes por atingirem no mercado preços bem mais altos do que os peixes (ex: camarões branco e especialmente o rosa). Assim, há uma frota quase que exclusivamente dedicada à pesca dos camarões. Essa frota realiza arrastos duplos de fundo com o uso de tangones e, por ter sua atividade intimamente ligada à pesca do camarão, é denominada de camaroeira.

A captura de crustáceos de meados da década de 80 ao início da década de 90 apresentou alguma oscilação nas imediações de 1989 , porém, com uma clara tendência decrescente de 1984 (mais de 8 mil toneladas) a 1993 (menos de 4 mil toneladas) (Figura 3). Ao contrário da pesca de crustáceos, a pesca de moluscos tem sido bastante variável entre 1984 e 1993 (0,5 a 1,2 mil toneladas), e não apresenta portanto nenhuma tendência geral (Figura 3). Os desembarques anuais de moluscos são baseados principalmente em duas espécies de lulas do gênero Loligo. Entretanto, é válido ressaltar que ocorrem ainda desembarques em menor escala de polvos.

\section{Os Tipos de Pescarias e a Frota Pesqueira Industrial do Litoral Centro-Norte Catarinense}

A captura do pescado descarregado em Santa Catarina é realizada basicamente através de nove tipos de pesca:

a ) arrasto de portas com duas embarcações - frota de parelhas;

b) arrasto de portas único - frota de arrasteiros simples;

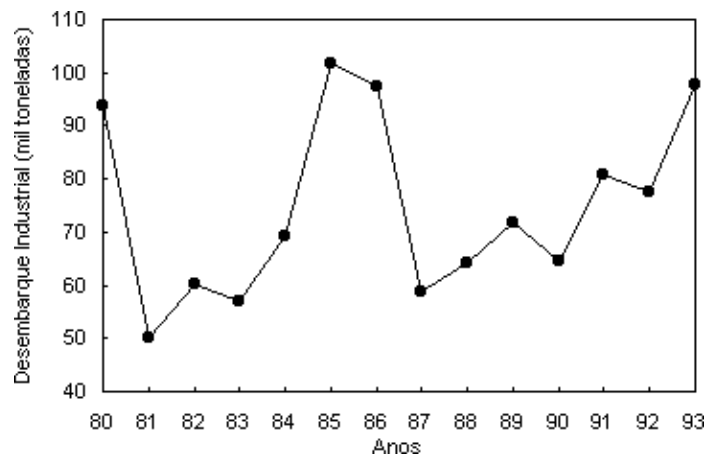

Figura 1: Desembarque total de pescado (toneladas) realizado pelas frotas artesanal e industrial no estado de Santa Catarina entre os anos de 1984 e 1993 (Fonte de Dados: CEPSUL/IBAMA, 1994).

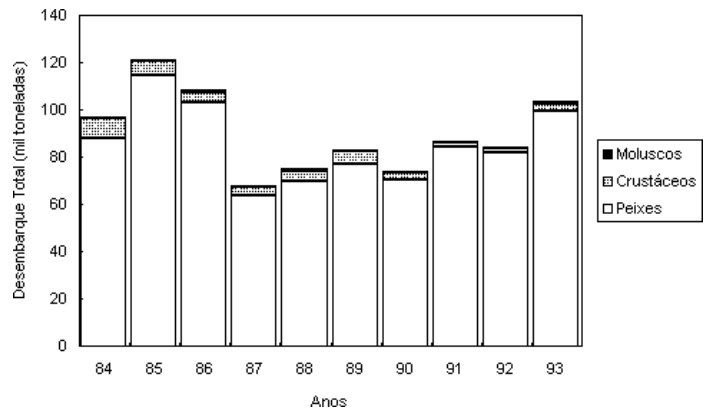

Figura 2: Captura total de pescado (toneladas) de 1984 a 1993, pelas frotas industriais e artesanais do Estado de Santa Catarina (Fonte de dados: CEPSUL/IBAMA, 1994).

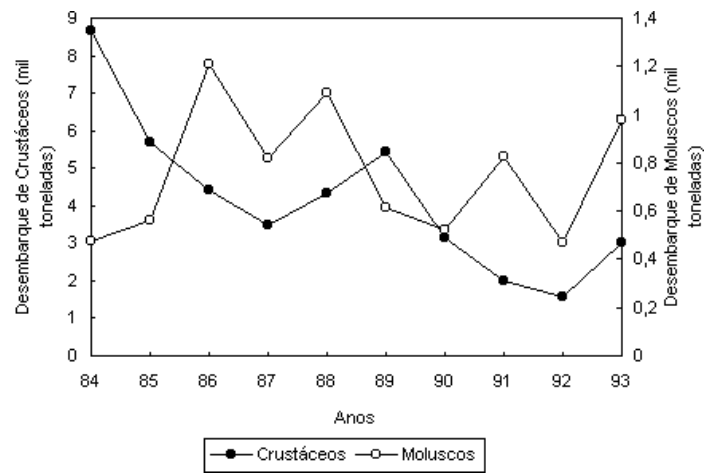

Figura 3: Captura total de crustáceos e moluscos (toneladas) de 1984 a 1993, pelas frotas industriais e artesanais do Estado de Santa Catarina (Fonte de dados: CEPSUL/IBAMA, 1994). 
c ) arrasto de portas com tangones - frota de camaroeiros;

d ) rede de emalhar flutuante e de fundo - frota de caceio;

e ) rede de cerco - frota de traineiras;

f) espinhel de meia água e de fundo - frota de espinheleiros;

g ) vara e isca-viva - frota de vara e isca-viva;

h ) linha de fundo - frota de linheiros;

i ) pargueira ou boinha - frota de pargueiros;

Apesar da grande diversidade de frotas e apetrechos de pesca, a maioria da captura em peso é realizada por três frotas, traineiras, parelhas e vara e isca-viva. As demais têm menor importância em termos de quantidade desembarcada (Figura 4). A captura anual realizada pela frota de traineiras variou entre 25.000 e 50.000 toneladas. Após um pequeno incremento de 1988 a 1989, houve uma queda em 1990 (25.000 toneladas) e posteriormente um incremento nos anos seguintes, sendo que a partir de 1992 os desembarques foram superiores a 45.000 toneladas (Figura $4 a)$.

Não houveram grandes variações nos desembarques da frota de vara e isca-viva entre 1988 e 1993, as capturas foram de aproximadamente 15.000 toneladas anuais. As capturas anuais da frota de parelhas também não sofreram grandes variações entre 1988 e 1992, quando mantiveram-se entre 10.000 e 15.000 toneladas. Entretanto houve um incremento significativo da captura em 1993, com um desembarque anual de mais de 20.000 toneladas (Figura 4a). Entre as demais frotas, destaca-se a tendência constante de queda de captura da frota camaroeira de 1988 (6.000 ton.) a 1992 (2.000 ton.) e a pequena recuperação em 1993 (3.000 ton.) (Figura 4b). Os desembarques de arrasteiros simples apresentaram um aumento de 1989 a 1990, e posteriormente poucas variações até 1993. As pescarias de espinhéis e de caceio, talvez por terem alvos similares (peças grandes com alto valor comercial), apresentaram padrões muito semelhantes de desenvolvimento entre 1988 e 1993. Houveram pequenas variações até 1992, com baixas capturas (inferiores a mil toneladas), e alguma tendência de incremento pouco expressiva para a pesca de caceio. Em 1993 houve uma explosão de ambas as pescarias, com capturas de cerca de 4 mil toneladas para a frota de caceio e de cerca de 2 mil toneladas para a frota de espinheleiros (Figura 4b). Os registros de desembarques de linheiros e pargueiros são muito pequenos quando comparados com os demais.

A pescaria de traineiras resulta nas maiores capturas (Figura 4a), porém é a que emprega o maior esforço pesqueiro em termos de número de desembarques, enquanto que as frotas de parelhas e vara e isca-viva que apresentam capturas razoáveis, apresentam comparativamente um menor número de desembarques anuais (Figura 5). A frota de camaroeiros por sua vez não apresenta um grande desembarque em peso (Figura 4b), porém emprega um grande esforço pesquei-

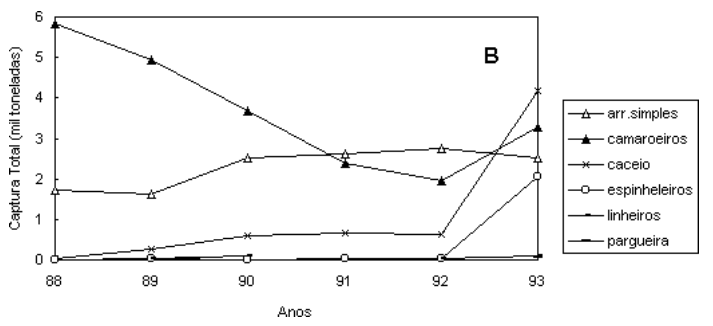

Figura 4: Captura total de pescado descarregado por frota em Santa Catarina de 1988 a 1993 (Fonte de dados: CEPSUL/IBAMA, 1994). 
ANDRADE: A produção da pesca industrial em Santa Catarina.

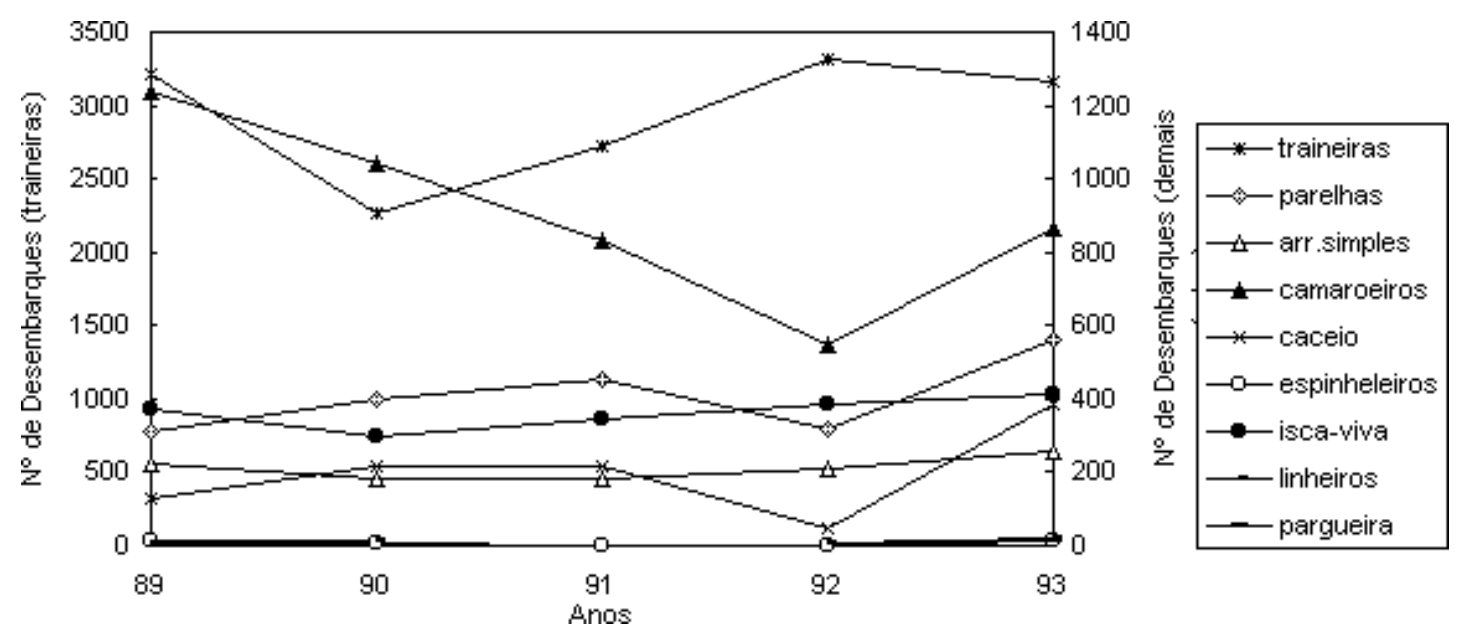

Figura 5: Número de desembarques por frota em Santa Catarina de 1989 a 1993 (Fonte de dados: CEPSUL/IBAMA, 1994).

ro em termos de número de desembarques (Figura 5). No entanto, é importante ressaltar novamente que o número de desembarques não é uma unidade de esforço muito adequada para comparação das dados de diferentes frotas. Entretanto, o uso do número de desembarques como unidade de esforço de pesca é válido para avaliação da variação temporal da pescaria de uma determinada frota. Dessa forma chama a atenção a grande queda no número de desembarques de traineiras em 1990 e posterior recuperação até 1992 . Outra feição importante é a queda pronunciada no número de desembarques dos camaroeiros de 1989 a 1992, com um posterior incremento em 1993. As variações no número de desembarques de parelhas e caceio foram bastante semelhantes, ocorrendo incrementos suaves de 1989 a 1990, uma queda pequena até 1992 e um incremento mais pronunciado em 1993. O número de desembarques das frotas de vara e isca-viva e de arrasteiros simples, não sofreram grandes alterações durante o período analisado (Figura 5).

A captura por unidade de esforço (CPUE) em termos de toneladas por desembarque das frotas de vara e isca-viva e de parelhas são consideravelmente superiores às
CPUEs das demais pescarias (Figura 6). Apesar da unidade de esforço não ser adequada a análise das variações temporais da CPUE de uma determinada frota pode ser feita sem maiores restrições.

Nas oscilações das CPUEs das diversas frotas, destaca-se a tendência de queda de rendimento de 1990 a 1992 da frota de vara e isca-viva, o grande incremento nos rendimentos dos espinheleiros de 1990 a 1992 e da frota de caceio de 1991 a 1992. Em menor escala é evidente também um incremento na CPUE das traineiras de 1990 a 1991, e dos arrasteiros simples de 1989 a 1990 e uma queda na CPUE dessa frota de 1992 a 1993. Os rendimentos das demais frotas ou não mostraram uma tendência clara ou não apresentaram realmente grandes variações interanuais, com a CPUE mantendo-se em níveis semelhantes durante todo o período analisado (Figura 6). O cálculo da CPUE para a pesca de espinhel em 1993 não é mostrado uma vez que há um erro no dado de esforço e/ou de captura, o que determina a obtenção de uma CPUE improvável, extremamente alta.

A análise para todas as frotas das variações percentuais da captura, esforço de pesca e CPUE em relação ao primeiro ano da 

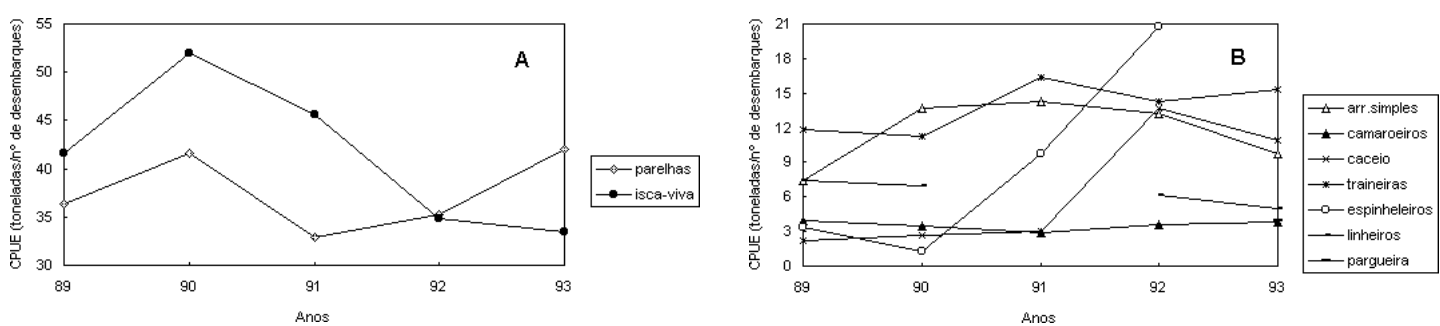

Figura 6: Captura por Unidade de Esforço (CPUE) em termos de toneladas por desembarque entre 1989 e 1993 em Santa Catarina (Fonte de dados: CEPSUL/IBAMA, 1994).

série temporal analisada, torna mais fácil a interpretação dos resultados (Figura 7).

De 1989 a 1990 a queda na captura das traineiras, superou a queda do esforço de pes$\mathrm{ca}$, de forma que a CPUE acabou por mostrar um pequeno decréscimo de cerca de $5 \%$. Em 1991, primeiro ano do emprego do defeso de recrutamento no início do inverno (Andrade, 1997), o incremento nas capturas foi grande e em conseqüência, apesar do incremento no esforço de pesca, a CPUE apresentou um crescimento. De 1991 a 1993, a CPUE respondeu de forma inversa as tendências do esforço de pesca. A continuidade de crescimento no esforço de pesca em 1992, resultou em decréscimo da CPUE. Posteriormente, um pequeno decréscimo no esforço de pesca em 1993, esteve associado a um incremento suave da CPUE (Figura 7).

No caso da pesca de vara e isca-viva as tendências do esforço de pesca e da CPUE foram completamente inversas durante o período analisado. Até 1990 houve um incremento na CPUE, vinculado ao decréscimo no esforço de pesca. Posteriormente tendências crescentes do esforço de pesca até 1993, implicaram em queda acentuada da CPUE (Figura 7).

Nas pescarias baseadas em arrastos de fundo, arrastos simples, de parelhas, e de camaroeiros, houveram algumas diferenças no desenvolvimento das CPUEs durante o período analisado. As CPUEs da frota de pareIhas não mostraram variações significativas, que evidenciassem alguma tendência definida. A pesca por camaroeiros apresentou variações interessantes. Houve uma tendência de decréscimo grande dos esforços de pesca de 1989 a 1992. Apesar disso a CPUE caiu também até 1991, e aparentemente respondeu ao decréscimo no esforço de pesca somente em 1992, quando os níveis de explotação haviam sido reduzidos em mais de $50 \%$. Aparentemente essa recuperação dos rendimentos implicaram em novo entusiasmo e incremento conspícuo no esforço de pesca em 1993, o que resultou em resposta de diminuição imediata na taxa de crescimento da CPUE (Figura 7). As variações encontradas na pesca dos arrasteiros simples mostraram um padrão claro de relação negativa do esforço de pesca com a CPUE. Incrementos no esforço de pesca implicaram em diminuições na CPUE, e vice-versa.

A pescaria da frota de caceio apresentou no geral as mesmas tendências inversas de esforço de pesca e CPUE, principalmente a partir de 1991, quando uma diminuição e um incremento subseqüente no esforço de pesca, estiveram associados a um incremento e posterior decréscimo da CPUE (Figura 7). As pescarias de espinheleiros e linheiros não foram exceções, em ambas foi aparente que reduções e incrementos nos esforços de pesca, implicam em reduções e incrementos na CPUE, respectivamente (Figura 7). Dentro dessa perspectiva, é válido destacar o incre- 
ANDRADE: A produção da pesca industrial em Santa Catarina.
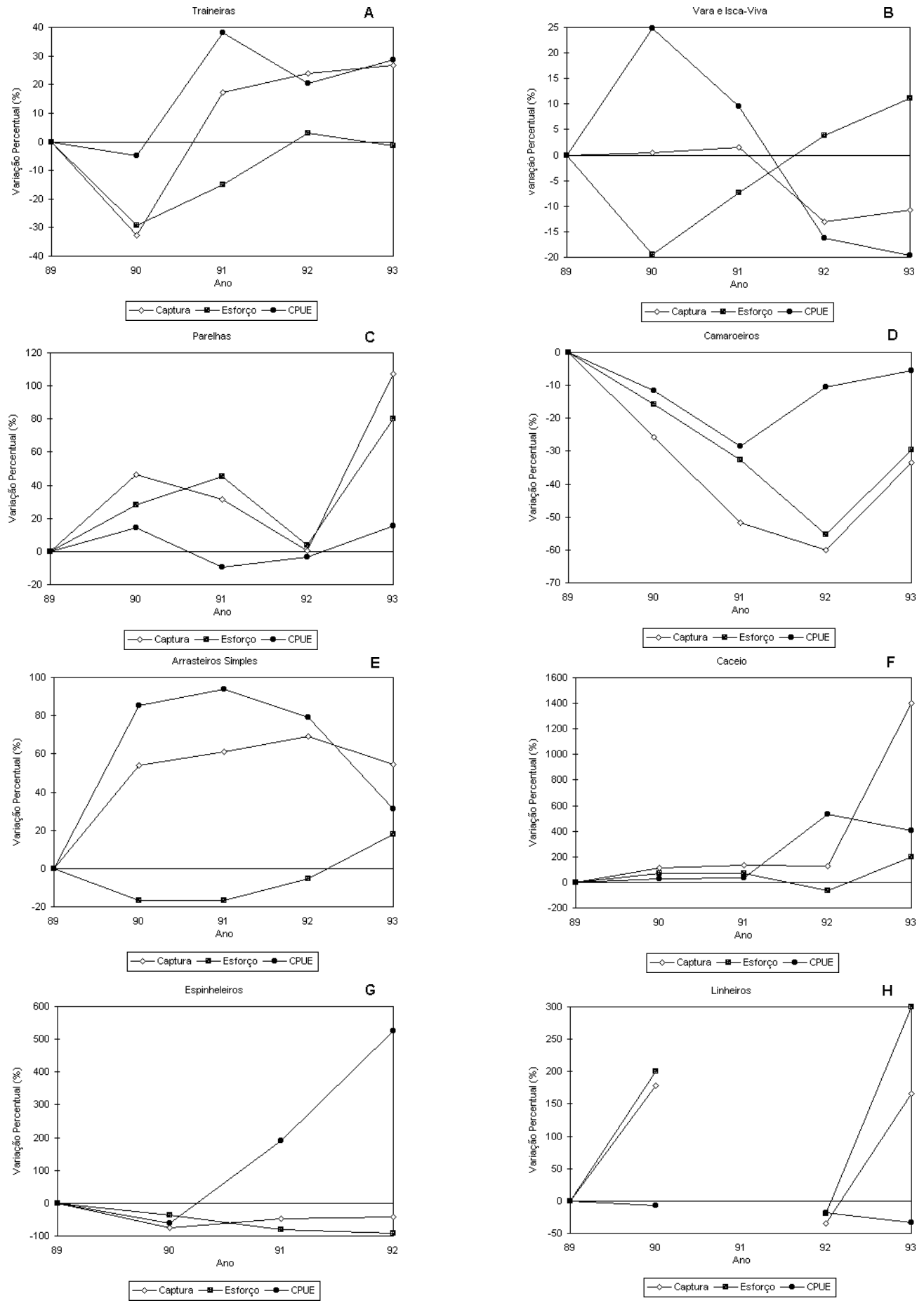

Figura 7: Variação percentual das capturas, dos esforços de pesca e das CPUEs (ton/no de desembarque) das principais frotas, em relação a 1989. (A) Traineiras; (B) Vara e Isca-Viva; (C) Parelhas; (D) Camaroeiros; (E) Arrasteiros Simples; (F) Caceio; (G) Espnheleiros; (H) Linheiros (Fonte de Dados: CEPSUL/IBAMA, 1994). 
mento muito grande da CPUE de espinheleiros no início da década de 90 (Figura 7).

O efeito da influência da pescaria de traineiras para o desembarque total de pescado em Santa Catarina pode ser visualizado através da Figura 8. Quando considerada conjuntamente com as demais pescarias (Figura 8 a), as tendências da pesca de traineiras determinam tendências inclusive contrárias às apresentadas por todas as demais frotas conjuntamente (Figura $8 \mathrm{~b}$ ). Quando considerada a pesca de traineiras, conjuntamente com as demais, houve inversões das tendências gerais de captura em 1990, de captura, CPUE e esforço em 1991, CPUE e esforço em 1992, e CPUE em 1993 (Figuras 8a e 8b).

\section{Principais Espécies e Artefatos de Pesca Utilizados para Captura}

O setor industrial captura aproximadamente 120 espécies, porém a grande maioria da captura é baseada em cerca de 28 espécies (Tabela 1). A sardinha e o bonito listado constituem os dois principais recursos pesqueiros para o Estado de Santa Catarina. Entre as demais espécies de peixes pelágicos destacam-se a sardinha lage, o chicharro, a palombeta e a tainha. Entre as espécies de

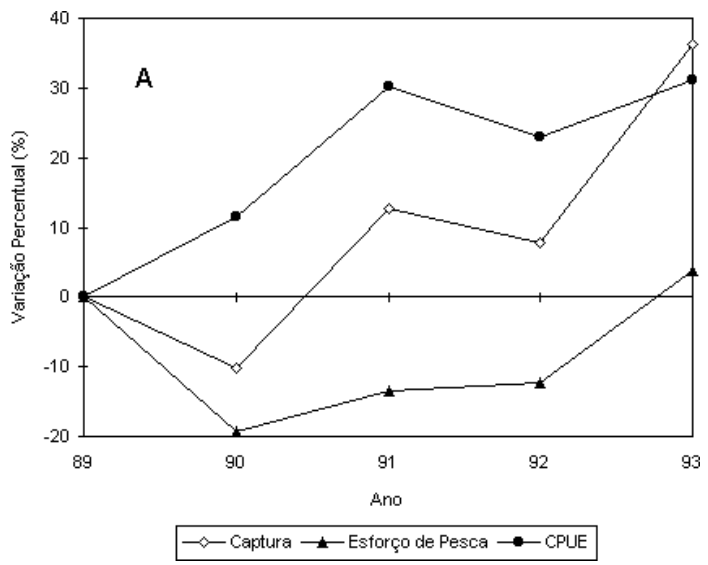

peixes demersais destacam-se a corvina, a castanha, a pescadinha real, e a pescada olhuda. Entre os elasmobrânquios, o principal recurso pesqueiro é sem dúvida o cação anjo, e entre os moluscos, a lula. Na pescaria de crustáceos tem destacada importância a captura dos camarões sete-barbas, santana e rosa (Tabela 1).

Algumas espécies têm a maioria de sua captura realizada por um único artefato de pesca, enquanto outras são pescadas por mais de uma frota. Da mesma forma existem frotas que capturam basicamente uma única espécie, e frotas que capturam normalmente uma grande diversidade de espécies (multiespecíficas). Apesar da sardinha verdadeira ser a espécie alvo e constituir a maioria da captura, as sardinhas lage e cascuda, o chicharro, a palombeta, a tainha, a cavalinha e a enchova são também capturadas por traineiras, principal frota para a captura dessas espécies (Tabela 1). Os arrastos de parelhas são responsáveis pela maior parte da captura dos demersais, como a corvina, a castanha, a pescadinha real, a pescada olhuda, o peixe porco, o goete e o papa-terra. Os camarões sete-barbas, santana e rosa são capturados basicamente por arrastos com o uso de tangones, o que justifica a denominação de

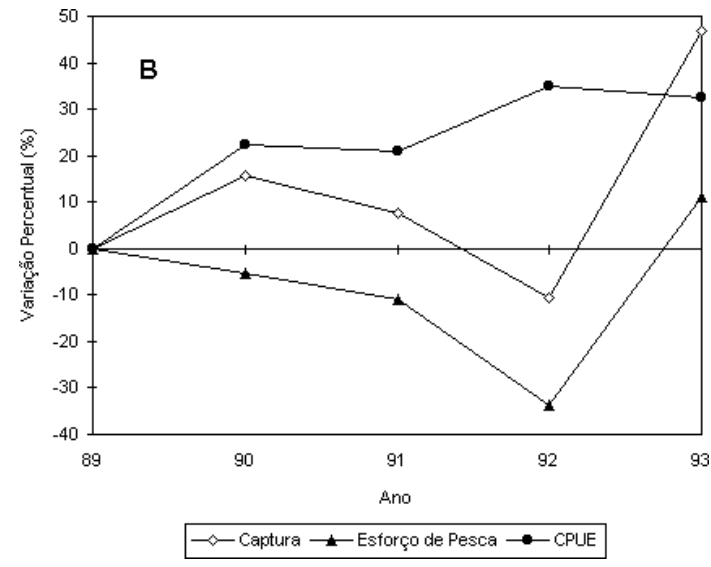

Figura 8: Variação percentual das capturas, dos esforços de pesca e das CPUEs (ton/nํ desembarque) das principais frotas, em relação a 1989. (A) Dados totais de todas as frotas; (B) Excluídos os dados da frota de traineiras (Fonte de Dados: CEPSUL/IBAMA, 1994). 
ANDRADE: A produção da pesca industrial em Santa Catarina.

frota camaroeira para essas embarcações. Finalmente, a maior parte das capturas dos tunídeos, bonito listado e albacora lage, é realizada através da pesca de vara e isca-viva (Tabela 1).

Outros recursos pesqueiros são pescados mais eqüitativamente por mais de uma frota pesqueira. Entre estes, destacam-se o cação anjo, cações em geral, a lula, o bagre, a abrótea, o bonito cachorro, o linguado e a cabrinha (Tabela 1). Nesse caso, o acompanhamento temporal das capturas de um dado recurso por parte das diferentes frotas pesqueiras, é essencial para o entendimento da evolução da pescaria.

\section{DISCUSSÃO}

Uma vez que a série temporal avaliada é bastante curta, a análise dos resultados obtidos não leva a resultados conclusivos e deve ser cautelosa. No entanto algumas questões podem ser levantadas. As variações quanto ao total descarregado no estado de Santa Catarina refletem basicamente o comportamento das frotas de pesca que têm os peixes como principal alvo (Figuras 1 e 2 e Tabela 1). Apesar da pouca contribuição em volume, as pescarias de crustáceos, calcadas na captura de camarões, têm destacada importância econômica em virtude do alto preço do produto no mercado, com especial distinção para o camarão rosa.

A queda observada até 1990, e mesmo a oscilação em torno de 1989 no total de crustáceos desembarcados em Santa Catarina (Figura 3), refletem principalmente as variações das capturas dos camarões sete-barbas, que em termos de volume de pescado constitui o principal entre os crustáceos (IBAMA, 1993 a; Andrade, 1997).

Apesar de não haver perspectivas futuras positivas para a captura dos camarões sete-barbas e rosa, houve um leve incremento nos desembarques gerais de crustáceos no litoral centro-norte catarinense em 1993 (Fi- gura 3), derivado da pesca do camarão santana ou vermelho (Andrade, 1997). Os desembarques desta espécie a nível nacional mostraram uma grande queda de 1988 a 1990 , porém ultimamente vêm crescendo (CEPSUL/ IBAMA, 1994 a e b), em virtude do desvio do esforço de pesca para sua captura, de parte da frota anteriormente dedicada à pesca de outros camarões, principalmente do rosa. Apesar do camarão santana apresentar um preço de comercialização relativamente mais baixo, atualmente este recurso tem se mostrado mais abundante que o camarão rosa, razão que possibilita maiores capturas e compensa 0 menor preço atingido no mercado.

A pescaria de moluscos, baseada na captura de lulas, contribui pouco para a captura anual total. No entanto, uma espécie (Loligo plel) tem destacada importância em virtude da sazonalidade demarcada de sua ocorrência, o que deu origem inclusive a uma pescaria dirigida. Outro aspecto que torna essa pescaria importante, é a coincidência de sua safra com a queda na safra do camarão rosa e eventualmente com o início do período de defeso do camarão (Pezzuto et al., 1996; Andrade, 1997). As oscilações interanuais das capturas são características comuns de pescarias de lulas e podem ser principalmente decorrentes do fato de que as lulas têm um ciclo de vida curto e um único pulso reprodutivo anual. Dessa forma, o sucesso ou fracasso de um recrutamento é provavelmente determinante para as CPUEs obtidos no ano subsequente (Perez, com. pess.) e, portanto, para as oscilações das capturas ao longo de uma série temporal. Entretanto, não há uma pescaria direcionada durante todo 0 ano, o esforço de pesca investido, é dependente de uma sazonalidade intrínseca quanto à abundância do recurso e de períodos de rendimentos baixos na pesca de outras espécies. Isto não é incomum no caso da frota camaroeira, que freqüentemente tem a lula como alternativa na época de final da safra do camarão e de defeso do camarão rosa, basicamente no outono. A conjunção da variabilidade intrínse- 
Tabela 1: Principais espécies capturadas e artefatos usados pelo setor industrial no Estado de Santa Catarina entre os anos de 1988 e 1993. (Fonte de dados: CEPSUL/IBAMA, 1994).

\begin{tabular}{|c|c|c|}
\hline Espécie & $\begin{array}{l}\text { Captura Total (ton.) } \\
(1988-1993)\end{array}$ & Principal Artefato de Pesca \\
\hline $\begin{array}{l}\text { Sardinha Verdadeira (Sardinella } \\
\text { brasiliensis) }\end{array}$ & $177.986,6$ & rede de cerco (traineiras) \\
\hline $\begin{array}{l}\text { Bonito Listado (Katsuwonus } \\
\text { pelamis) }\end{array}$ & $81.619,9$ & vara e isca-viva \\
\hline Corvina (Micropogonias furnierı) & $15.332,9$ & $\begin{array}{l}\text { arrasto de portas (parelhas) e rede de } \\
\text { cerco (traineiras) }\end{array}$ \\
\hline Castanha (Umbrina canosal) & $14.749,7$ & $\begin{array}{l}\text { arrasto de portas (parelhas e arrastos } \\
\text { simples) }\end{array}$ \\
\hline $\begin{array}{l}\text { Sardinha Lage (Ophistonema } \\
\text { oglinum) }\end{array}$ & $12.247,7$ & rede de cerco (traineiras) \\
\hline Chicharro (Trachurus lathami) & $12.140,6$ & rede de cerco (traineiras) \\
\hline $\begin{array}{l}\text { Pescadinha Real (Macrodon } \\
\text { ancylodon) }\end{array}$ & $7.684,7$ & arrasto de portas (parelhas) \\
\hline $\begin{array}{l}\text { Pescada Olhuda (Cynoscion } \\
\text { striatus) }\end{array}$ & $6.706,1$ & arrasto de portas (parelhas) \\
\hline $\begin{array}{l}\text { Palombeta (Chloroscombrus } \\
\text { chrysurus) }\end{array}$ & $6.406,5$ & rede de cerco (traineiras) \\
\hline $\begin{array}{l}\text { Camarão Sete Barbas } \\
\text { (Xiphopenaeus kroyerı) }\end{array}$ & $5.834,6$ & arrasto de portas (tangones) \\
\hline Tainha (Mugil spp.) & $4.675,1$ & rede de cerco (traineiras) \\
\hline $\begin{array}{l}\text { Albacora Lage (Thunnus } \\
\text { albacares) }\end{array}$ & $3.895,9$ & vara e isca-viva \\
\hline Cação Anjo (Squatina spp.) & $3.727,5$ & $\begin{array}{l}\text { rede de emalhe (caceio) e arrasto de } \\
\text { portas (arrastos simples) }\end{array}$ \\
\hline Cavalinha (Scomber japonicus) & $3.686,3$ & rede de cerco (traineiras) \\
\hline $\begin{array}{l}\text { Cações (espécies de } 7 \text { famílias } \\
\text { agrupadas) }\end{array}$ & $3.671,6$ & $\begin{array}{l}\text { rede de emalhe (caceio) e arrasto de } \\
\text { portas (parelhas) }\end{array}$ \\
\hline $\begin{array}{l}\text { Peixe Porco (Balistes capriscus e } \\
\text { Alutera monocerus) }\end{array}$ & $3.208,2$ & arrasto de portas (parelhas) \\
\hline $\begin{array}{l}\text { Camarão Santana (Pleoticus } \\
\text { muellerı) }\end{array}$ & $2.997,6$ & arrasto de portas (tangones) \\
\hline Enchova (Pomatomus saltatrix) & $2.870,4$ & rede de cerco (traineiras) \\
\hline Goete (Cynoscion jamaicensis) & $2.797,0$ & arrasto de portas (parelhas) \\
\hline $\begin{array}{l}\text { Lula (principalmente espécies da } \\
\text { família Loliginidae) }\end{array}$ & $2.427,9$ & arrasto de portas (tangones e parelhas) \\
\hline Bagre (espécies da família Ariidae) & $2.315,5$ & $\begin{array}{l}\text { arrasto de portas (parelhas) e rede de } \\
\text { cerco (caceio) }\end{array}$ \\
\hline $\begin{array}{l}\text { Abrótea (Urophycis brasiliensis e } \\
\text { U.mystaceus) }\end{array}$ & $2.077,8$ & $\begin{array}{l}\text { arrasto de portas (parelhas e arrastos } \\
\text { simples) e rede de emalhe (caceio) }\end{array}$ \\
\hline $\begin{array}{l}\text { Papa Terra (Menticirrhus } \\
\text { americanus e M.littoralis) }\end{array}$ & $2.071,7$ & arrasto de portas (parelhas) \\
\hline $\begin{array}{l}\text { Camarão Rosa (Penaeus } \\
\text { paulensis e P.brasiliensis) }\end{array}$ & $2.063,8$ & arrasto de portas (tangones) \\
\hline Bonito Cachorro (Auxis thazard) & $1.705,0$ & rede de cerco (traineiras) e vara e isca-viva \\
\hline $\begin{array}{l}\text { Sardinha Cascuda (Harengula } \\
\text { clupeola) }\end{array}$ & $1.560,6$ & rede de cerco (traineiras) \\
\hline $\begin{array}{l}\text { Linguado (espécies de pelo menos } \\
7 \text { gêneros, principalmente } \\
\text { Paralichthys spp.) }\end{array}$ & $1.552,7$ & $\begin{array}{l}\text { arrasto de portas (arrastos simples, } \\
\text { parelhas e camaroeiros) }\end{array}$ \\
\hline $\begin{array}{l}\text { Cabra (Prionotus punctatus e } \\
\text { P.nudigula) }\end{array}$ & $1.351,3$ & $\begin{array}{l}\text { arrasto de portas (arrastos simples e } \\
\text { parelhas) }\end{array}$ \\
\hline
\end{tabular}


ca do recurso, com a estratégia da frota pesqueira é provavelmente a causa das grandes oscilações interanuais da captura total de moluscos (Figura 3).

As variações do total descarregado em Santa Catarina são dependentes basicamente das capturas de peixes e devem portanto serem investigadas sob esse prisma. Os últimos relatórios dos Grupos Permanentes de Estudo sobre as principais pescarias de peixes da costa sudeste e sul do Brasil indicam que atualmente a maioria dos recursos encontra-se próximo de níveis de super-explotação com tendências de queda nas capturas e CPUEs das pescarias (IBAMA, $1993 \mathrm{a}, \mathrm{b}$ e c). Portanto, a tendência observada de aumento no peso total desembarcado entre 1980 e 1985, e posteriormente de 1987 a 1993 (Figura 1), não deve a princípio ser considerada como resultado de um incremento na abundância das espécies tradicionalmente explotadas. Esse crescimento tem sido atribuído basicamente ao aumento no esforço de pesca (IBAMA, 1993 a, b e c), e ao incremento no número de desembarques realizados nos portos do estado, principalmente nas cidades de Itajaí e Navegantes, por embarcações que anteriormente descarregavam em outros portos (Branco, E. J. com. pess.).

Pelo menos de 1988 a 1993, as frotas de traineiras principalmente, e em segunda instância de parelhas e vara e isca-viva (Figura 4a), foram as determinantes para as variações observadas da captura geral (Figura 1 e Tabela 1), as demais frotas apresentaram capturas anuais inferiores a 6 mil toneladas durante o período analisado (Figura 4b). As oscilações da captura (incremento de 1988 a 1989, queda em 1990 e incremento em 1991) (Figura 1) refletem basicamente as variações da captura da frota de traineiras (Figura 4a). Essas oscilações são em parte resposta às variações no número de desembarques (Figura 5), porém estão também influenciadas pela CPUE (Figura 6), que a exemplo do número de desembarques mostrou uma queda de 1989 a 1990, e posterior incremento a partir de então.

O incremento no esforço de pesca de traineiras a partir de 1990 (Figura 7a) constitui um exemplo clássico da resposta do setor produtivo pesqueiro frente a determinação de períodos de defeso (proibição temporária da pesca). A pescaria da sardinha, espécie alvo da pesca de traineiras (Tabela 1), tinha como único período de defeso até 1990 as proximidades do verão (principal período de desova da espécie). A partir de 1991 foi implementado um defeso de recrutamento no início do inverno. Como resposta houve um grande incremento do esforço de pesca em 1991 e 1992, com posterior estabilização em 1993 em patamares semelhantes aos existentes antes da implementação do segundo período de defeso. A diminuição da temporada permitida de pesca, não resulta necessariamente em médio prazo na diminuição do esforço de pesca despendido. Deve ser sempre considerada a resposta comportamental dos pescadores, de tendência de aumento no esforço despendido nas épocas permissionadas para compensação das épocas em que não é permitida a pescaria.

Após 1991, as variações na captura total não podem ser consideradas inteiramente um reflexo das capturas da frota de traineiras. A queda subseqüente da captura total em 1992 é aparentemente um efeito conjunto de pequenas quedas nas capturas das pescas de vara e isca-viva, parelhas, camaroeiros e secundariamente de caceio (Figura 4). No caso dessas três últimas frotas citadas, o decréscimo nas capturas é explicado por uma diminuição do esforço de pesca em 1992 (Figura 5). Para essas frotas de parelhas, camaroeiros e caceio houve inclusive um incremento na CPUE (Figura 6). Esse não foi o padrão encontrado para a pesca de vara e isca-viva, que apesar de apresentar uma queda da captura em 1992 (Figura 4), apresentou também um incremento do esforço de pesca (Figura 5), o que determinou um decréscimo acentuado da CPUE até 1992 (Figura 6). 
A queda nas capturas e CPUEs da pescaria de vara e isca-viva provavelmente não é derivada de uma diminuição na abundância do bonito listado (espécie alvo), uma vez que o mesmo tem sido considerado como subexplotado nas avaliações pesqueiras realizadas na costa oeste e leste do Atlântico (Jablonsky e Matsuura, 1985; Vilela, 1990; Kleiber e Fonteneau, 1994). Essa queda na CPUE pode ser considerada como resultado de oscilações naturais, e não há portanto perspectivas de que essa tendência de decréscimo se mantenha ainda nos anos subseqüentes. Para esclarecer essa questão é importante a continuidade do acompanhamento da CPUE, com o uso de uma unidade de esforço mais adequada, como por exemplo captura por dias de pesca. Essa questão enfatiza novamente a fragilidade de análises de séries temporais pequenas e a necessidade premente de um acompanhamento sistemático intensivo de pesca, que possibilite análises mais conclusivas, de maior utilidade para a administração pesqueira.

O incremento nas capturas em 1993, outra feição não justificada totalmente pelas variações nas capturas das traineiras, é também um efeito combinado de incrementos nas capturas de quase todas as frotas, com destaque para as frotas de parelhas, caceio, camaroeiros e espinheleiros (Figura 4). Os incrementos das capturas dessas frotas em 1993 estão associados aos aumentos dos esforços de pesca nesse ano (Figura 5). No caso das pescarias de parelhas e camaroeiros os aumentos do peso total desembarcado (Figura 5) estão associados também a incrementos das CPUEs (Figura 6). Entretanto para a frota de caceio, ao contrário, houve uma queda evidente da CPUE em 1993. A análise de CPUE para a frota de espinheleiros não pode ser feita em 1993, uma vez que há algum erro ou no dado de número de desembarques ou de captura anual, que resultaram em um cálculo de CPUE extremamente alto, completamente improvável.
As tendências de grande crescimento das capturas das frotas de caceio e de espinheleiros, a partir do final da década de 80 , principalmente em 1993, evidenciam o recente interesse despertado por essas linhas de produção (poucas peças grandes de grande valor comercial) e conseqüentemente o incremento de investimentos e de esforço nessas pescarias.

No caso da pesca de caceio, apesar de aparentemente termos uma tendência positiva de desenvolvimento, as perspectivas para o futuro não são muito promissoras. A pesca de emalhe por barcos de caceio tem como alvo espécies de elasmobrânquios. Este grupo de peixes, tem como característica geral uma baixa taxa de crescimento, aliada a um ciclo de vida longo e uma baixa fecundidade, o que torna-os recursos de alta fragilidade (Holden, 1974; Vooren, 1991; IBAMA, 1993 c). Reconhecidamente, pressões de pesca exacerbadas, levam invariavelmente a diminuições substanciais na abundância, o que reflete nos baixos rendimentos pesqueiros subseqüentes. Uma vez diminuída a abundância do recurso, a recuperação, mesmo sob regime de baixo esforço de pesca é lenta, em virtude de seu longo ciclo de vida. Devido a essa fragilidade, historicamente a pesca de cações, tubarões e raias no sul do Brasil tem mostrado estar fadada ao colapso, caso não seja administrada adequada e rigorosamente, haja visto, por exemplo, a pescaria de caceio sediada no estado do Rio Grande do Sul (Vooren, 1991).

Face à problemática exposta acima e ao estágio em que se encontra a pescaria em Santa Catarina, ainda emergente e em franco desenvolvimento, é evidente a necessidade de obtenção rápida de conhecimentos biológicos relevantes à administração da pescaria de elasmobrânquios. A questão é complexa uma vez que a pescaria é caracteristicamente multiespecífica e tem como principal alvo espécies do gênero Squatina e Sphyrna (Kotas et al., manuscrito).

A tendência de crescimento das capturas totais gerais de 1989 a 1993 (Figura 1), 
não pode ser atribuída completamente a incrementos no esforço de pesca. Até 1992, as variações positivas (crescimento) dos esforços de pesca ocorreram somente no caso da frota de parelhas (Figura 7). Incrementos significativos do esforço de pesca para as demais frotas ocorreram no geral somente em 1993 (Figura 7), quando então o crescimento da captura total (Figura 1), esteve associado às variações do esforço de pesca.

Com exceção das frotas de traineiras e parelhas, as demais frotas mostraram nitidamente tendências temporais inversas entre esforço de pesca e rendimento (Figura 7). Este comportamento indica que provavelmente essas pescarias se encontram em pontos muito próximos do rendimento máximo possível. Uma conclusão mais concreta sobre essas pescarias somente será possível mediante uma análise calcada em dados mais detalhados de esforço de pesca. Nesse aspecto está incluído a problemática da estratégia de direcionamento sazonal da frota e do direcionamento sobre espécies alvo e a realização de captura incidental de outras espécies (Andrade et al., 1997). Este último ponto evidencia a necessidade da consideração da multi-especificidade para avaliação de uma série de pescarias. De todas as pescarias abordadas somente as pescarias de traineiras, voltada à captura da sardinha (Sardinella brasiliensis), e vara e isca-viva, voltada à captura do bonito listado (Katsuwonus pelamis), podem ser consideradas para fins práticos de cálculo como uni-específicas (Tabela 1).

No caso das parelhas, a pescaria não tem mostrado relações inversas entre esforço e rendimento (Figura 7), provavelmente por duas causas: a) Aproveitamento nos desembarques de espécies que antigamente eram tidas como rejeito e praticamente descartadas em suas totalidade (i.e. cabrinha - Prionotus spp.). Essa colocação é também válida para as demais pescarias de arrasto de fundo; e b) A pescaria de parelhas é provavelmente a de maior caráter multi-específico, e reconhecidamente pescarias tropicais desse tipo freqüentemente não respondem a aumentos no esforço de pesca com queda no rendimento (Pauly, 1984; Sparre et al., 1989). O que normalmente ocorre nesses casos é um decréscimo da captura de indivíduos maiores de idades mais avançadas, um conseqüente decréscimo do comprimento médio capturado, um incremento na contribuição relativa dos peixes menores e de espécies economicamente menos significantes, pela remoção de predadores e decréscimo da competição (Pauly, 1984).

No caso das traineiras a aparente inexistência de uma relação inversa entre esforço e rendimento, principalmente em 1991, quando houve crescimento concomitante de ambos, é provavelmente um efeito positivo do defeso de recrutamento (início do inverno) implementado em 1990 (Figura 7). A partir de 1991, as tendências das variações de esforço e rendimento apresentaram o comportamento padrão de relação inversa. A série temporal é pequena, o que limita a análise, principalmente para espécies com ciclo de vida curto, que apresentam reconhecidamente grandes flutuações naturais, como é o caso da sardinha, espécie alvo das traineiras (Tabela 1). Essas flutuações estão normalmente associadas a sucessos e fracassos de recrutamento. Apesar da incerteza introduzida, devido à pequena série temporal, é evidente que o defeso de recrutamento em 1990 foi positivo e possibilitou o estabelecimento dos rendimentos de pesca em um patamar mais elevado (Figura 7). Devido à sua importância em peso total descarregado, o incremento nas capturas de traineiras em 1991 (Figura 7), provavelmente resultante do defeso recém implementado, foi decisivo para o incremento geral de pescado no ano de 1991 (Figura 1). Esse incremento da pescaria de traineiras em 1991, chega a mascarar as tendências gerais de captura, esforço e CPUE apresentadas pelas demais frotas (Figura 8). 


\section{CONCLUSÕES}

As variações da produção catarinense de pescado, refletem em primeira instância as capturas de peixes pelas frotas de traineiras, parelhas e vara e isca-viva.

A maioria das pescarias apresentaram o padrão comum de relação inversa entre o esforço despendido e o rendimento. $\mathrm{O}$ ano de 1991 da pesca de traineiras foi uma exceção, explicada pela implementação do defeso em 1990. Outra exceção ocorreu para a pesca de parelhas, explicada aparentemente pelo caráter extremamente multi-específico dessa pescaria.

As oscilações e a tendência geral crescente de produção de pescado de 1989 a 1993, até 1991 é basicamente reflexo das variações na pesca de traineiras. Entretanto 0 incremento em 1993 é resultante de aumento generalizado dos esforços de pesca, com grande desenvolvimento das pescarias de caceio e espinheleiros. Outro fator que contribuiu também para a tendência geral crescente de 1989 a 1993 é provavelmente o aproveitamento nas pescarias de arrasto de fundo de espécies que antigamente eram tidas como rejeito.

\section{AGRADECIMENTOS}

À Fundação Banco do Brasil que financiou e propiciou a execução desse trabalho.

\section{REFERÊNCIAS BIBLIOGRÁFICAS}

Andrade, H. A. 1997. Relatório do Projeto Integrado da Foz do Rio Itajaí-Açu e Área Costeira Adjacente: Diagnóstico e Avaliação Ambiental. Sub-Projeto: A Pesca no Litoral Centro-Norte Catarinense. Fundação Banco do Brasil. $98 \mathrm{pp}$.

Andrade, H. A.; Perez, J. A. A.; Pezzuto, P. R. \& Ribeiro, M. R. 1997. A Dinâmica
Temporal da Pesca Industrial de Santa Catarina: Recursos Demersais. Anais do VII Congresso Latinoamericano de Ciencias del Mar. Outubro, Santos-SP.

CEPSUL/IBAMA, 1994 a. Informe sobre os Desembarques Controlados de Pescados no Estado de Santa Catarina, nos Anos de 1988 a 1992. Itajaí. 101 pp.

CEPSUL/IBAMA, 1994 b. Desembarques Controlados de Pescados. Estado de Santa Catarina - 1993. Coleção Meio Ambiente. Série Estudos - Pesca, № 14., IBAMA, Brasília. 132 pp.

Holden, M. J. 1974. Problems in the Rational Explotation of Elasmobranch Populations and Some Suggested Solutions. p. 117137. In F. R. Harden Jones [Ed.], Sea Fisheries Research. Johm Wiley \& Sons, New York.

IBAMA, 1993 a. Relatório da IX Reunião do Grupo Permanente de Estudos (GPE) de Camarões do Sudeste e Sul. Coleção Meio Ambiente. Série Estudos - Pesca, № 5., Brasília. 63 pp.

IBAMA, 1993 b. Relatório Preliminar da Reunião do Grupo Permanente de Estudos (GPE) da Sardinha. Coleção Meio Ambiente. Série Estudos - Pesca, № 4., Brasília. 41 pp.

IBAMA, 1993 c. Relatório da III Reunião do Grupo Permanente de Estudos (GPE) sobre Peixes Demersais. Coleção Meio Ambiente. Série Estudos - Pesca, № 8., Brasília. 93 pp.

Jablonski, S. \& Matsuura, Y. 1985. Estimate of Exploitation Rates and Population Size of Skipjack Tuna Off The Southeastern Coast of Brazil. Bol. Inst. oceanogr., S.Paulo, 33(1):29-38.

Kotas, J. E.; Rocha-Gamba, M.; Conolly, P. C.; Hostim-Silva, M.; Mazzoleni, R. C. \& Pereira, J. (manuscrito). Gillnet Activities in Southern Brasil. 49 pp.

Kleiber, P. \& Fonteneau, A. 1994. Assessment of Skipjack Tuna Interaction in the Eastern Tropical Atlantic using Tagging Data. FAO.Fish.Tech.Pap. (336/1): 94-107. 
Pauly, D. 1984. Fish Population Dynamics in Tropical Waters: A Manual for Use with Programmable Calculators. ICLARM Stud.Rev. (8):325 pp.

Pezzuto, P. R.; Perez, J. A. A. \& Ribas, T. M. 1996. A Dinâmica da Captura de Invertebrados de Valor Comercial pela Frota Camaroneira de Santa Catarina. Anais do III Simpósio sobre Oceanografia - IOUSP. Dezembro, São Paulo, SP.

Sparre, P.; Ursin, E. \& Venema, S. C. 1989. Introduction to Tropical Fish Stock Assessment. FAO.Fish.Tech.Pap. (306/1): $429 \mathrm{pp}$.
Vilela, M. J. A. 1990. Idade, Crescimento, Alimentação e Avaliação do Estoque de Bonito Listado, Katsuwonus pelamis (Scombridae: Thunnini), Explorado na Região Sudeste-Sul do Brasil. Tese de Mestrado. Universidade do Rio Grande, RS, Brasil. $81 \mathrm{pp}$.

Vooren, C. M. 1991. Pesca e Conservação: os Elasmobrânquios do Sul do Brasil. Anais do II Congresso Internacional de Gestion en Recursos Naturales. p. 56. Valdívia, Chile. 